\title{
Morfologia de sementes e desenvolvimento pós-seminal de Physalis angulata $\mathrm{L}$.
}

\author{
Cíntia Luiza Mascarenhas de Souza ${ }^{1,4}$, Manuela Oliveira de Souza ${ }^{2}$, Milene Fonseca de Oliveira ${ }^{1}$, \\ Lenaldo Muniz de Oliveira ${ }^{3}$ e Claudinéia Regina Pelacani ${ }^{1}$
}

Recebido em 26/04/2010. Aceito em 06/12/2010

\begin{abstract}
RESUMO - (Morfologia de sementes e desenvolvimento pós-seminal de Physalis angulata L.) Physalis angulata é conhecida como camapu, mullaca ou juá-de-capote e pertence à família Solanaceae. Esta espécie possui importância medicinal, pela presença dos vitaesteróides conhecidos como fisalinas e, atualmente, na alimentação. Essa espécie se propaga facilmente por sementes, motivo pelo qual ela é tida como infestante de outras culturas. Nesse sentido, a identificação da espécie ainda nos estágios iniciais de crescimento confunde com as demais infestantes, tornando difícil a sua caracterização taxonômica. Assim, o objetivo deste trabalho foi caracterizar morfologicamente as sementes e o desenvolvimento pós-seminal de Physalis angulata. Os ensaios foram desenvolvidos no Laboratório de Germinação da Unidade Experimental Horto Florestal, Feira de Santana - BA. Para tanto foram realizadas análises morfométricas das sementes (4 repetições de 25) e analisadas suas características externas e internas com auxilio de microscópico estereoscópico. Para a descrição das plântulas da espécie foram utilizadas placas de petri contendo duas folhas de papel filtro (4 repetições de 20 sementes) e umedecidos com água destilada. As sementes foram colocadas em câmara de germinação à $35^{\circ} \mathrm{C}$ (fotoperíodo de 12 horas) até a emissão dos cotilédones. A metodologia para descrição do desenvolvimento pós-seminal foi realizada em condições de casa de vegetação e consistiu em avaliações realizadas cinco dias após a semeadura (emissão dos cotilédones) e no intervalo de até 15 dias (emissão de eófilos e metáfilos) no qual foram utilizados 2 repetições de 20 vasos. As sementes apresentaram em média 1,55 $\mathrm{mm}$ de comprimento, $1,26 \mathrm{~mm}$ de largura e $0,43 \mathrm{~mm}$ de espessura. O período de análise foi suficiente para caracterizar as sementes e plântulas da espécie, permitindo a adoção de critérios de anormalidade.
\end{abstract}

Palavras-chave: Morfometria, tegumento, embrião, cotilédones, plântulas

ABSTRACT - (Seed morphology and post-seminal development of Physalis angulata L.). Physalis angulata is also known as camapu, mullaca or juáde-capote it belongs to the Solanaceae family. This species has its medicinal importance due to vitasteroids presence known as physalins, and currently due to its use as food. It propagates readily by seed, which is the reason why it is regarded as weeds in other crops. Accordingly, the identification of that species in the early stages of growth is indistinguishable from other weeds, hindering taxonomic characterization. Thus, the objective of this study was to morphologically characterize seeds and post-seminal development of Physalis angulata. The tests were developed in the Laboratory of Germination of the Experimental Unit/Nursery, in Feira de Santana/BA. Therefore, we have performed morphometric analysis of the seeds (4 replicates of 25 seeds) and we have analyzed their external and internal features with the aid of a stereoscopic microscope. For the description of the species seedlings it was used Petri dishes containing two sheets of filter paper (4 replicates of 20 seeds) and moistened with distilled water. The methodology for describing the post-seminal developmente was conduced under field conditions and consisted of evaluetions performed five days after sowing (inssuance of cotyledons) and the range of up to 15 days (and inssuing eophylls metaphylls) in which two replicates were used 20 pots. Assessments were performed five days after sowing (issuance of cotyledons) and ranging of up to 15 days (emission of eophylls and metaphylls). The seeds had an average of $1.55 \mathrm{~mm}$ long, $1.26 \mathrm{~mm}$ wide and $0.43 \mathrm{~mm}$ thick. The period of analysis was sufficient to characterize the seeds and seedlings of the species, applied as a criteria for abnormality. Key words: Morphometric, seed coat, embryo, cotyledon, seedlings

\section{Introdução}

Physalis angulata é conhecida como camapu, mullaca ou juá-de-capote. Pertence à família Solanaceae A. L. Jussieu, que é uma das maiores dentre as angiospermas. Essa família com 150 gêneros e cerca de 3.000 espécies tem a América do Sul como um dos centros de diversidade e endemismo (Hunziker, 2001; Souza \& Lorenzi, 2005). Com distribuição tropical e subtropical, são 110 espécies, ocorrendo principalmente na Ásia, Europa e Estados Unidos. No Brasil podem ser encontradas 11 espécies (Sendter, 1846; D'arcy et al. 2005), distribuídas por todo o país com ênfase para a Amazônia e Nordeste (6 espécies).

Do ponto de vista medicinal é utilizada popularmente como anticoagulante, diurético, antiinflamatório, dentre outros. Entretanto, já existem pesquisas de cunho científico que apontam esta espécie como potencialmente anticarcinogênica (Ribeiro et al., 2002).

No que diz respeito a seu hábito, trata-se de uma planta herbácea, ereta, medindo 40-70 cm de comprimento (Lorenzi
\& Matos, 2008), podendo alcançar dois metros se conduzida por tutoramento, sendo anual e reproduz-se por semente. As folhas são pubescentes, alternas, e as formas variam de obovada a ovada lanceolada ou amplamente ovalada a estreita elíptica (Gonem et al. 2000; Silva \& Agra, 2005). As flores são solitárias, cálice soldado até a metade e permanece nos frutos, a corola é gamopétala amarelada ( $1 / 4$ do interior do tubo marrom), anteras azuladas ou violetas, dorsifixas (Gonem et al. 2000; Silva \& Agra, 2005).

Possui um ciclo relativamente curto, produzindo a maior quantidade de frutos (do tipo baga com cálice crescente) em média aos 90 dias após a semeadura. Os frutos são pequenos e redondos, com coloração alaranjada quando maduros, envolvidos por sépalas em forma de balão (Freitas \& Osuña, 2006).

As sementes, enquanto estruturas de dispersão, representam o ponto de interseção entre duas gerações. Por isso, estas têm características ecofisiológicas próprias, germi-

\footnotetext{
1 Universidade Estadual de Feira de Santana, Unidade Experimental Horto Florestal, Laboratório de Germinação, Feira de Santana, BA, Brasil

2 Universidade Estadual de Feira de Santana, Programa de Pós-Graduação em Biotecnologia, Feira de Santana, BA, Brasil

3 Universidade Estadual de Feira de Santana, Unidade Experimental Horto Florestal, Laboratório de Cultura de Tecidos Vegetais, Feira de Santana, BA, Brasil

4 Autor para correspondência: timluiza@gmail.com
} 
nando apenas em condições favoráveis. Através do estudo da morfologia de sementes e plântulas é possível analisar o ciclo vegetativo da espécie e também obter informações sobre germinação, armazenamento, viabilidade, dentre outros fatores (Rego et al., 2007). As características morfológicas de uma espécie são importantes para sua identificação botânica. A capacidade de reconhecimento das plântulas e dos estádios juvenis num determinado ecossistema pode ter um grande valor nos estudos ecológicos e de sucessão (Rego et al., 2007).

Segundo Barroso (1999), é imprescindível conhecer a estrutura das sementes, pois, a partir delas podem-se obter dados importantes a respeito da germinação, armazenamento, viabilidade e métodos de semeadura. A germinação é um processo que envolve inúmeras reações bioquímicas, principalmente de translocação de compostos orgânicos que culminam com o desenvolvimento do eixo embrionário e a protrusão da radícula. A morfologia interna e externa das sementes, assim como a observação das plântulas, fornece subsídios para interpretação de testes de germinação e realização de trabalhos científicos (Araújo \& Matos, 1991). Assim, o objetivo deste trabalho foi caracterizar morfologicamente as sementes e o desenvolvimento pós-seminal de Physalis angulata L.

\section{Material e métodos}

Os frutos de Physalis angulata foram coletados manualmente em setembro de 2007 no Horto Florestal da Universidade Estadual de Feira de Santana de plantas cultivadas em casa de vegetação. As sementes foram retiradas sob água corrente até a separação completa da polpa. Estas foram colocadas para secar sobre papel filtro em temperatura ambiente (condições de laboratório) e foram armazenadas, nas mesmas condições, em recipiente de vidro contendo sílica, que era trocada cada vez que esta se mostrava hidratada, até o momento dos ensaios. As sementes foram caracterizadas quanto ao teor de água (\%) e tamanho. Para o teor de água, foram avaliadas quatro amostras de 50 sementes, utilizando-se o método estufa a $60^{\circ} \mathrm{C}$ até obtenção do peso constante, sendo as variações medidas a cada dois dias. Morfologia da Semente

Foram observadas e ilustradas, com auxilio de microscópio estereoscópico, descritas as características externas e internas das sementes:

a) Características Externas

Para as análises morfométricas foram retiradas 100 sementes (4 repetições de 25) aleatoriamente, medindo-se o comprimento (medida do ápice à base), a largura e a espessura (região mediana) de cada uma com o auxílio de paquímetro digital e microscópio estereoscópico. Coloração e textura do tegumento, forma das sementes, posição do hilo e da micrópila foram analisadas.

b) Características Internas

Através de cortes transversais e longitudinais, feitos com auxílio de lâminas de aço, foram analisadas a forma, cor e posição dos cotilédones, do eixo embrionário e do endosperma.

Morfologia do desenvolvimento pós-seminal

O início da embebição das sementes até a emissão dos cotilédones foi observado, com avaliações realizadas a cada hora e confecção de ilustrações nas seguintes etapas: sementes embebidas, protrusão da raiz primária, alongamento do hipocótilo, lançamento dos cotilédones. As ilustrações foram feitas à mão livre, apresentadas na forma de prancha sobre papel e em grafite.

As sementes foram colocadas em câmara de germinação regulada para $35^{\circ} \mathrm{C}$ (fotoperíodo de 12 horas). Foram utilizadas placas de petri ( 6 X 6 $\mathrm{cm}$ ) contendo duas folhas de papel filtro (4 repetições de 20 sementes) e umedecidos com água destilada (2,5 vezes o peso do substrato) (BRASIL, 1992) até a emissão dos cotilédones.
Concomitantemente, outro grupo foi semeado em vasos de $2,5 \mathrm{Kg}$ (2 repetições de 20 sementes), nos quais as análises eram diárias, desde o aparecimento dos cotilédones até a emissão dos metáfilos. Avaliou-se os dias após a semeadura (D.A.S) necessários para que as mudas atingissem cada uma das etapas.

As descrições das características internas e externas de plantas e sementes estão de acordo com Barroso (1999), Ferri et al. (1981), Castellani et al. (2008), Mourão et al. (2007).

\section{Resultados e discussão}

As sementes de Physalis angulata pesaram em média $0,025 \mathrm{~g}$ (50 sementes) e apresentaram 7\% de teor de água. São elipsóides e comprimidas, castanho alaranjadas quando completamente maduras e esbranquiçadas quando ainda imaturas. Apresentam em média $1,55 \mathrm{~mm}$ de comprimento, $1,26 \mathrm{~mm}$ de largura e $0,43 \mathrm{~mm}$ de espessura. Mais de $50 \%$ das sementes apresentaram comprimento entre 1,41 e 1,60 mm, e a faixa de variação da espessura se mostrou muito pequena, sendo mantida entre 0,34 à 0,51 mm (Figura 1). Estas observações estão de acordo com Martínez (1998), que descreveu as sementes de espécies do gênero Physalis com amarelo claras a marrom e o tamanho variando de $0,6-3,0 \mathrm{~mm}$ no comprimento. Segundo a autora todas as espécies apresentam sementes reniformes, exceto $P$. parvianthera.

Devido ao tamanho diminuto, muitas de suas características são visíveis apenas com o auxílio de miscroscópio estereoscópio. O tamanho das sementes de Physalis angulata explicam porque diferentes lotes de sementes da espécie, com diferentes períodos de armazenamento e submetidos a tratamentos de recuperação do vigor alcançam a fase II da embebição apenas 1 hora após o início do experimento. Esse fato corrobora a importância do conhecimento da morfologia das sementes para a explicação de testes de germinação. Assim como em Solanum pseudoquina A.St-Hil (tomatinho), Solanum lycocarpum A.St-Hil (lobeira) e Solanum granuloso-leprosum Dunal (gravitinha) (CASTELLANI et al., 2008), o hilo localiza-se em uma suave depressão na região mediano-marginal da semente, ao lado da micrópila (Figura 2A). O tegumento é glabro e reticulado na semente seca, sendo que após a embebição apresenta-se parcialmente liso e então permite a visualização do embrião.

Quanto à forma e posição do embrião ele é dicotiledonar, cilíndrico, axial e contínuo linear e envolto pelo endosperma. Este é esbranquiçado na semente seca ou semitransparente de consistência gelatinosa quando embebida. $\mathrm{O}$ embrião apresenta-se hialino e é considerado curvo conforme Barroso (1999). Entretanto, concordando com estudos realizados por Castellani et al. (2008) com espécies de Solanum, o embrião pode ser caracterizado como circinado (Figura 2B). O padrão de embebição das sementes de uma determinada espécie também é influenciado pela forma como suas reservas são armazenadas. Segundo Pereira et al. (2008), ao final da I fase da embebição sementes endospérmicas, como é o caso de Physalis angulata, atingem um grau de umidade de 25 a $30 \%$. 

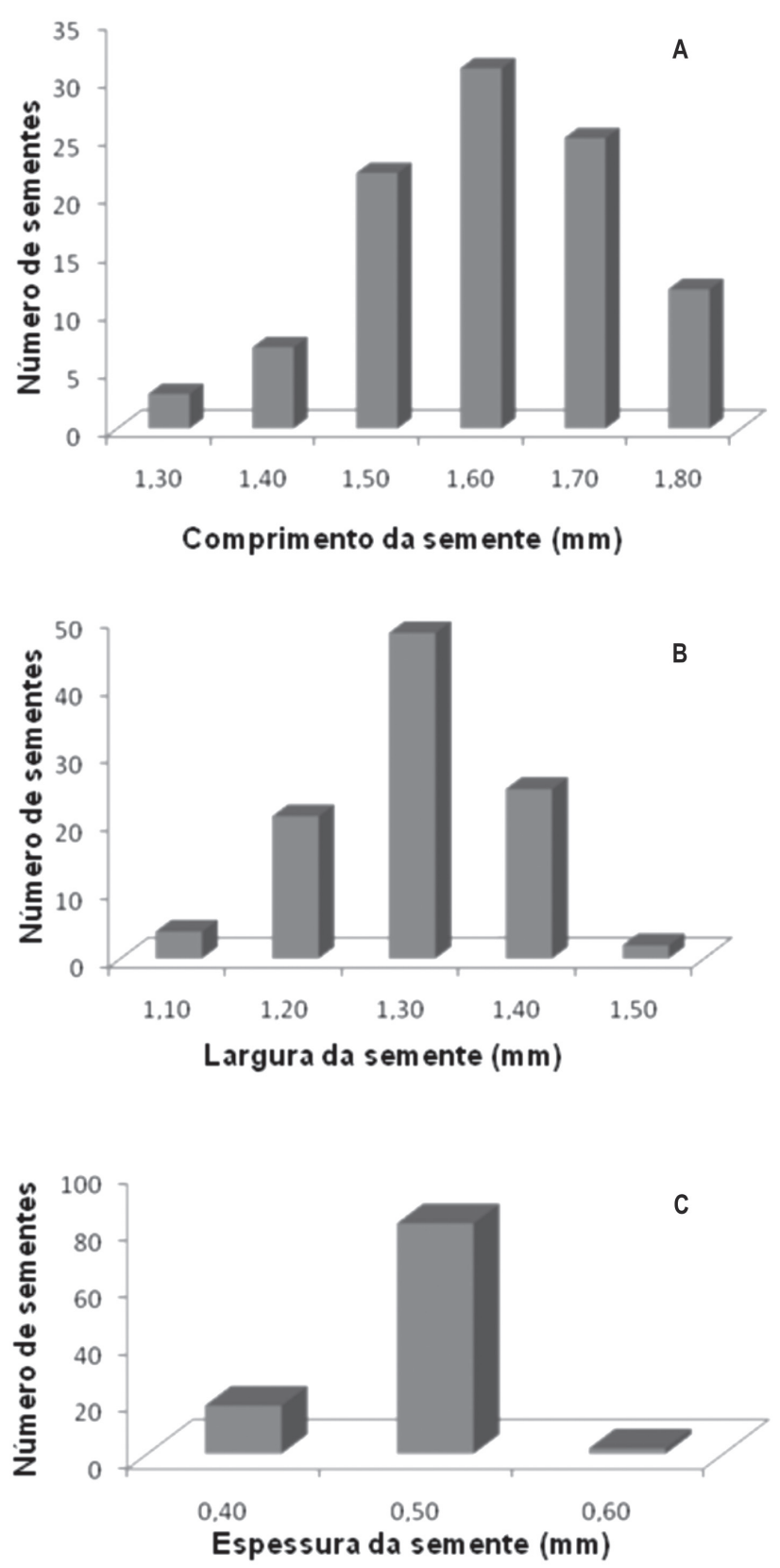

Figura 1. Comprimento (A), Largura (B) e espessura (C) das sementes de Physalis angulata L. (Solanaceae). Feira de Santana, Bahia, Brasil. Média de 4 repetições.

As sementes secas de Physalis angulata ficam completamente túrgidas uma hora após contato com a água. Cerca de 12 horas após o início do experimento já é possível visualizar o embrião através do tegumento. A protrusão radicular iniciou-se após 40 horas e o aparecimento dos primeiros pêlos na radícula foram observados com 52 horas. Com 78 horas de embebição as primeiras plântulas já apresentavam cotilédones parcialmente verdes e eram vistos através do tegumento, sugerindo presença de clorofila; com 80 horas os cotilédones e o hipocótilo já estavam completamente verdes. A liberação dos cotilédones do tegumento ocorreu 100 horas após o início do experimento.
Utilizando classificação de Miquel (1987) e descrição de Mourão et al. (2007), as plântulas de Physalis angulata são do tipo epígeo-foliácea (fanerocotiledonar, epígea com cotilédones foliáceos). Quando semeadas em vasos a emergência dos cotilédones ovados ocorreu em média aos 5 dias (D.A.S.). As margens dos cotilédones mostraram-se inteiras (Figura 2C), e estes permaneceram na planta adulta. O primeiro eófilo, cordato ou cordiforme de margem inteira, pôde ser visto no oitavo dia e, no décimo dia, estava completamente expandido, em consonância com o inicio do surgimento do segundo eófilo (filotaxia alterna) (Figura 2D). Após $13^{\circ}$ e $15^{\circ}$ dias começam a surgir os primeiro e segundo metáfilos (filotaxia alterna), elípticos de margem leve-dentada.

O estudo morfológico das espécies vem sendo realizado visando as mais diversas finalidades. Mesmo com o advento da biologia molecular a identificação taxonômica ainda é fundamental para o reconhecimento das espécies (AMARO et al., 2006; ABENSUR et al., 2007). Para Physalis angulata essa análise se mostrou essencial, pois torna possível o seu reconhecimento em campo ainda em seus estágios de desenvolvimento iniciais, além de distingui-la das demais espécies invasoras.

\section{Agradecimentos}

Ao CT-Biotecnologia/CT-Saúde/MCT/CNPq/MS/SCTIE/DECIT BIOINOVAn ${ }^{\circ}$ 20/2007 (Conselho Nacional de Desenvolvimento Científico e Tecnológico - CNPq) pela concessão da bolsa à primeira autora. A FAPESB pela concessão da bolsa de doutorado à segunda autora.Ao projeto Renorbio pelo auxilio financeiro e logístico. Aos pesquisadores Edson Ferreira Duarte e Lia d'Afonseca Miranda pelas contribuições.

\section{Referências Bibliográficas}

Abensur, F.O.; Melo, M.F.F.; Ramos, M.B.P.; Varela, V.P. \& Batalha, L.P. 2007. Tecnologia de sementes e morfologia da germinação de Jacaranda copaia D. Don (Bignoniaceae). Revista Brasileira de Biociências 5: 60-62.

Amaro, M.S.; Medeiros Filho, S.; Guimarães, R.M. \& Teófilo, E.M. 2006. Morfologia de frutos, sementes e plântulas de janaguma (Himatanthus drasticus (Mart.) Plumel. - Apocynaceae). Revista Brasileira de Sementes 28: 63-71.

Araújo, S.S.; Matos, V.P. 1991. Morfologia de sementes e de plântulas de Cassia fistula L. Revista Árvore 15: 217-223.

Barroso, G.M. 1999. Frutos e sementes: morfologia aplicada à sistemática de dicotiledôneas. Vicosa, UFV.

Brasil. Ministério da Agricultura e Reforma Agrária. 1992. Regras para análise de sementes. Brasília, SNDA/DNDV/CLAV.

Castellani, E.D.; Damião Filho, C.F.; Aguiar, I.B. \& César de Paula, R. 2008. Morfologia de frutos e sementes de espécies arbóreas do gênero Solanum L. Revista Brasileira de Sementes 30: 102-113.

D'arcy, W.; Rojas, C.B. \& Nee, M.H. 2005. Solanaceae. Flora of the Venezuelas Guyana 9: 194-246.

Ferri, M.G.; Menezes, N.L.; Monteiro, W.R. 1981. Glossário Ilustrado de Botânica. São Paulo, Nobel.

Freitas, T.A. \& Osuña, J.T.A. 2006. Efeito do substrato e da luminosidade na germinação de sementes de Physalis angulata L. (Solanaceae). Sitientibus 6: 101-104.

Gonem, O.; Yildirim, A.; Uyugur, F.N. 2000. A New Record for the Flora of Turkey Physalis angulata L. (Solanaceae). Turk Journal Botanic 24: 299-301.

Hunziker, A.T. 2001. The genera of Solanaceae. Ruggell, A.R.G. Gantner Verlang K.G.

Lorenzi, H. \& Matos, F.J.A. 2008. Plantas medicinais do Brasil: Nativas e Exóticas. 2. ed. Nova Odessa, São Paulo, Instituto Plantarum. 

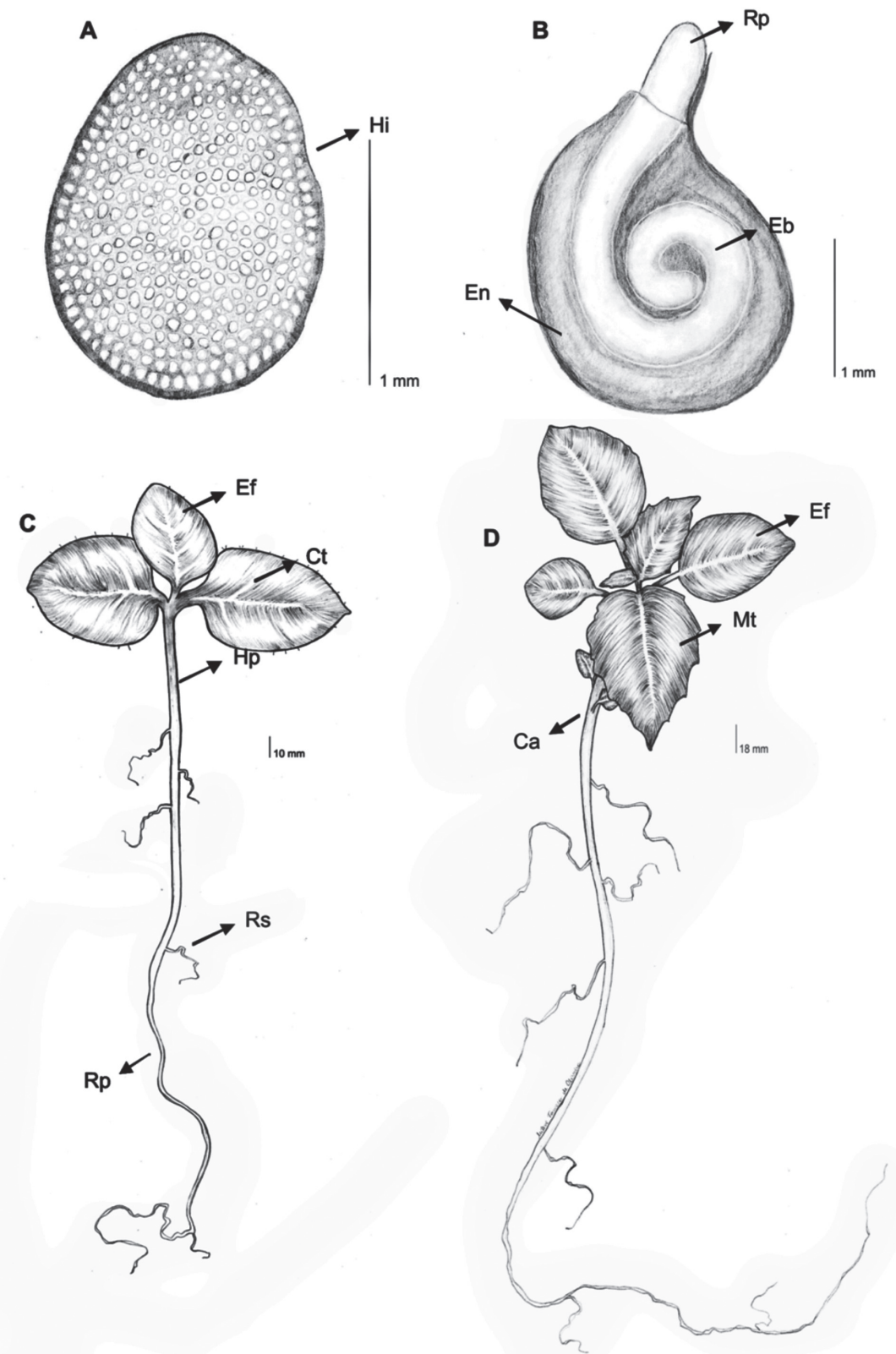

Figura 2. Sementes e plântulas de Physalis angulata L. (Solanaceae). Semente seca (A), Semente germinada (B), Plântula com dois cotilédones e um eófilo (C), Plântula com cotilédones, eófilos e metáfilos (D). Hi (hilo), Rp (raiz primária), Eb (embrião), En (endosperma), Ct (cotilédone), Hp (hipocótilo), Rs (raiz secundária), Ef (eófilo), Mt (metáfilo), Ca (caule). Por Milene Fonseca de Oliveira.

Martínez, M. 1998. Revision of Physalis section Epeteiorhiza (Solanaceae). Anales Del Instituto de Biologia Universidad Nacional Autônoma de México 2: 71-117.

Miquel, S. 1987. Morphologie fonctionelle de plantules d'especes forestiéres du Gabon. Bulletin of the National Science Museum 9: 101-121.

Mourão, K.S.M.; Domingues, L.; Marzinek, J. 2007. Morfologia de plântulas juvenis de espécies invasoras. Acta Scientiarum. Biological Sciences 29: 261- 268.

Pereira, M.D.; Dias, D.C.F.S.; Dias, L.A.S.; Araújo, E.F. 2008. Germinação e vigor de sementes de cenoura osmocondicionadas em papel umedecido e solução aerada. Revista Brasileira de Sementes 30: 137-145.

Rego S.S.; Silva, A.J.C.; Brondani, G.E.; Grisi, F.A.; Nogueira, A.C.; Kuniyoshi, Y.S. 2007. Caracterização morfológica do fruto, semente e germinação de Duranta vestita Cham. (Verbenaceae). Revista Brasileira de Biociências 5: 474-476.

Ribeiro I.M.; Silva, M.T.G.; Soares, R.D.A.; Stutz, C.M.; Bozza, M; Tomassini, T.C.B. 2002. Physalis angulata L. antineoplasic activity, in vitro, evaluation fromit's stems and fruit capsules. Revista Brasileira de Farmacognosia 12: 21-22.

Sendter, O. 1846. Solanaceae in: Martius Flora Brasiliensis 10: 6-200. Disponível em: $<$ http://florabrasiliensis.cria.org.br/fviewer $>$. (Acesso em: 16/02/2008).

Silva, K.N.; Agra, M.F. 2005. Estudo farmacobotânico comparativo entre Nicandra physalodes e Physalis angulata (Solanaceae). Revista Brasileira de Farmacognosia 15: 344-351.

Souza, V.C.; Lorenzi, H. 2005. Botânica sistemática: guia ilustrado para identificação das famílias de angiospermas da flora brasileira, baseado em APG II. Nova Odessa, Instituto Plantarum.

Versão eletrônica do artigo em www.scielo.br/abb e http://www.botanica.org.br/acta/ojs 